九州大学学術情報リポジトリ

Kyushu University Institutional Repository

\title{
Using Cut-Column Pollination Method to Overcome Crossing Barriers in Phalaenopsis Sunrise Goldmour 'KHM637'
}

Chuang, Hua-Ting

Laboratory of Floriculture, Department of HorticulturalScience, National Chiayi University

Huang, Kuang-Liang

Laboratory of Floriculture, Department of HorticulturalScience, National Chiayi University

Shen, Rong-Show

Laboratory of Floriculture, Department of HorticulturalScience, National Chiayi University

Miyajima, Ikuo

Institute of Tropical Agriculture, Kyushu University

他

https://doi.org/10.5109/1467626

出版情報：九州大学大学院農学研究院紀要. 59 (2)，pp.265-271，2014-08-29. Faculty of Agriculture, Kyushu University

バージョン :

権利関係 : 


\title{
Using Cut-Column Pollination Method to Overcome Crossing Barriers in Phalaenopsis Sunrise Goldmour 'KHM637'
}

\author{
Hua-Ting CHUANG ${ }^{1}$, Kuang-Liang HUANG ${ }^{1}$, Rong-Show SHEN ${ }^{1}$, \\ Ikuo MIYAJIMA ${ }^{2}$ and Shan-Te HSU ${ }^{1 *}$
}

\author{
Institute of Tropical Agriculture, Kyushu University, \\ Fukuoka 812-8581, Japan \\ (Received April 25, 2014 and accepted May 12, 2014)
}

\begin{abstract}
Crossing barriers occur frequently when crossing between commercial Phalaenopsis cultivars with desirable horticultural traits are attempted. In this study, Phalaenopsis Sunrise Goldmour 'KHM637', a tetraploid with $2 \mathrm{n}=4 \mathrm{x}=76$ chromosomes, known to be difficult in hybridization was chosen to examine crossing barriers and to explore the cut-column pollination method to overcome these barriers. $P$. Sunrise Goldmour 'KHM637' was either self-crossed, or used as the pollen or pistillate parent in reciprocal crossings with three tetraploid cultivars, including $P$. Brother Irene Irene 'Feng Fong', $P$. Sogo Yukidian 'V3', and $P$. Tai Lin Red Angel 'V31' that do not exhibit breeding barriers. Results showed that both stigma cavity closure and pollen tube growth did not occur when $P$. Sunrise Goldmour 'KHM637' was used as the pistillate parent. No offspring was obtained when using $P$. Sunrise Goldmour 'KHM637' as either pollen or pistillate parent. To explore performance of cut-column pollination method, $P$. Sunrise Goldmour 'KHM637' was used as the pistillate parent, after the removal of the upper part of column but with the stigma cavity intact, and then pollinated with pollinia of these three tetraploid cultivars and one species, $P$. violacea, respectively. The results showed that $22.2 \%-100.0 \%$ capsule sets were achieved from the four combinations, and offsprings were successfully obtained from three combinations. The authors suggested that the cut-column pollination method be applicable to other Phalaenopsis cultivars with similar crossing behaviors of $P$. Sunrise Goldmour 'KHM637' for overcoming the crossing barriers, and the applicability of the given method tended to be less limited to pollen parents without breeding barriers.
\end{abstract}

Key words: breeding barrier, maternal breeding barrier, reciprocal crossing, self-crossing, stigma cavity closure

\section{INTRODUCTION}

The Orchidaceae is one of the largest families of flowering plants with about 30,000 species classified into around 725 genera. The Phalaenopsis is a monopodial orchid in the Orchidaceae family. The genus Phalaenopsis comprising over 60 species belongs to the tribe Vandaeae under subfamily Vandoideae, which contains five subgenera, viz. subgenus Proboscidioides, subgenus Aphyllae, subgenus Parishianae, subgenus Polychilos, and subgenus Phalaenopsis (Christenson, 2001). Moth orchid is a common name for the genus Phalaenopsis. In commercial practice, plants of Phalaenopsis, Doritis and Doritaenopsis, an intergeneric hybrid between the former two genera, are collectively named as phalaenopsis orchids. At present, the Royal Horticultural Society (RHS) committee has decided to sink Doritis into Phalaenopsis; therefore Doritis and Doritaenopsis are now considered to be Phalaenopsis by RHS. Currently, more than 31,000 Phalaenopsis greges have been registered in RHS of UK (Royal

1 Laboratory of Floriculture, Department of Horticultural Science, National Chiayi University, Chiayi 60004, Taiwan (R.O.C.)

Institute of Tropical Agriculture, Kyushu University, Fukuoka 812-8581, Japan

* Corresponding author: Department of Horticultural Science, National Chiayi University, No.300 Syuefu Rd., Chiayi City 60004, Taiwan (R.O.C.), E-mail: hsust@mail.ncyu.edu.tw, telephone: +88652717423 , fax: +88652775472 .
Horticultural Society, 2013). Phalaenopsis orchid has been a favorite consumer product due to its attractive color, graceful and long-lasting flowers. Nowadays, pot phalaenopsis has become one of the most important orchids in the trade.

Through years of research and development of new cultivars and promotion of the phalaenopsis industry, the mass production of high quality phalaenopsis orchids has led Taiwan to be known as "the kingdom of Phalaenopsis". Phalaenopsis orchids are mainly exported to the United States, Japan, European Union, Korea and China. In 2011, its gross export value reached $\$ 98.5$ million USD (Customs Administration, Ministry of Finance, R.O.C., 2012). In order to increase its competitiveness in facing the challenge from international competition, the industry has to continuously develop excellent new cultivars in addition to mass production of seedlings with the highest quality. For developing new cultivars through conventional breeding, failures in producing capsules with fertile seeds are frequently encountered in intergeneric, inter- and intra-specific crossings of Phalaenopsis. It is not clear which type of incompatibility and incongruity may cause the barriers in breeding of Phalaenopsis and whether these barriers are caused by genetic or external factors. Until now, there are no complete and detailed studies in addressing these issues.

In order to elucidate the basis for the reproductive barriers between specific crossing combinations for getting new cultivars, the genetic and physiological characteristics of some Phalaenopsis cultivars were examined 
to identify the reproductive barriers between specific crossing combinations in our previous studies (Chuang et al., 2008; Hsu et al., 2010). These results indicated that crossing difficulties in those selected cultivars might be caused by odd chromosome set and some other factors of pollen or pistillate parents. The authors also demonstrated that the cut-column pollination method innovated in this study proved to overcome breeding barriers in Phalaenopsis Taipei Gold 'STM', a triploid with $2 \mathrm{n}=3 \mathrm{x}=57$ chromosomes, known to have stigma closure problem after pollination and be difficult in hybridization (Chuang et al., 2013). P. Sunrise Goldmour 'KHM637', a tetraploid with $2 \mathrm{n}=4 \mathrm{x}=76$ chromosomes, has also shown similar hybridization behaviors to $P$. Taipei Gold 'STM' (Chuang et al., 2008). Therefore, this study aimed to examine the efficacy of cut-column pollination method for overcoming the breeding barriers of $P$. Sunrise Goldmour 'KHM637', and to explore the applicable extensibility of the given method.

\section{MATERIALS AND METHODS}

\section{Plant material and cultivation conditions}

The mature clonal plants of Phalaenopsis Sunrise Goldmour 'KHM637' (SG), a tetraploid with 2n=4x=76 chromosomes, known to have stigma closure problem after pollination and to be difficult in hybridization (Chuang et al., 2008), P. Brother Irene Irene 'Feng Fong' (BII), $P$. Sogo Yukidian 'V3' (V3), $P$. Tai Lin Red Angel 'V31' (V31) and $P$. violacea were purchased or offered from several professional growers in Taiwan (Table 1) and grown in a greenhouse at Horticultural Technology Center, National Chiayi University, Chiayi, Taiwan, R.O.C.. For all experiments, plants were grown in a greenhouse at a temperature regime of $25 / 20^{\circ} \mathrm{C}$ day/night and a natural photoperiod $\left(23^{\circ} 47^{\prime} \mathrm{N}, 120^{\circ} 48^{\prime} \mathrm{E}\right)$ with a light intensity of 300 to $400 \mu \mathrm{mol} \cdot \mathrm{m}^{-2} \cdot \mathrm{s}^{-1}$ during 1000 to $1200 \mathrm{~h}$ on the sunny days

\section{Self- and reciprocal crossings}

First, all four cultivars presented in Table 1 were self-crossed to check their crossing behaviors. Next, the cultivar of SG with difficulty in hybridization was recip- rocal-crossed with each of the three normal cultivars, BII, V3 and V31. The occurrence of stigma cavity closure, in vivo pollen tube elongation, and capsule set were collected at three days after pollination (DAP), 7 DAP, and 60 DAP, respectively. The fertilities were evaluated by asymbiotic seed germinating abilities according to the method recommended by Lin et al. (2008). Two separate sets of experiments were conducted for investigating pollen tube development and fertility, respectively. Nine flowers randomly selected from three plants were examined in each self- and reciprocal crossings.

\section{Microscopic observation of pollen tube growth}

To monitor pollen tube behavior in different crossing combinations, columns were harvested evenly from nine flowers on three plants of each crossing seven days after pollination, fixed in FAA (formalin: acetic acid: 70\% ethanol=1:1:18) for $24 \mathrm{~h}$ at room temperature, and softened in $8 \mathrm{~N} \mathrm{NaOH}$ at $60^{\circ} \mathrm{C}$ for $1.5 \mathrm{~h}$. The samples were then stained with a $0.1 \%$ aniline blue solution (Kho and Baër, 1968) at $4^{\circ} \mathrm{C}$ for $24 \mathrm{~h}$, quashed onto slides in a drop of glycerin and observed under a fluorescent microscope (Zeiss Axioskop2, EM: BP 365 to $390 \mathrm{~nm}$ ). A pollen grain showing tube length exceeding twice its own diameter was considered germinated.

\section{Examining the efficacy of cut-column pollination method}

The cultivar of SG with difficulty in hybridization, used as the pistillate parent, was treated with cut-column pollination method used cultivars of BII, V3 and V31, and $P$. violacea as the pollen parents without breeding barriers, for evaluating the efficacy of the given method on overcoming the breeding barriers of SG. The procedures of cut-column pollination method used in this study were conducted as follows. 1. The sepals and petals of pistillate parent were removed from the base. 2. The upper part of column was cut off, with the stigma cavity intact. 3. Pollinia of pollen parent were then placed onto stigma cavity of pistillate parent. 4. The stigma cavity was subsequently sealed with paraffin film (Fig. 1). The occurrence of capsule set was collected at 60 DAP. The fertility and offspring production were examined by asym-

Table 1. Crossing performance, chromosome number and source of the Phalaenopsis cultivars/species used in this study

\begin{tabular}{|c|c|c|c|c|}
\hline Description & $\begin{array}{l}\text { Cultivar/species name } \\
\text { (abbreviation) }\end{array}$ & $\begin{array}{l}\text { Chromosome } \\
\text { number }\end{array}$ & Reference & $\begin{array}{l}\text { Source of plant } \\
\text { materials }\end{array}$ \\
\hline $\begin{array}{l}\text { Difficult in } \\
\text { hybridization }\end{array}$ & $\begin{array}{l}\text { Phalaenopsis Sunrise } \\
\text { Goldmour 'KHM637' (SG) }\end{array}$ & $2 n=4 x=76$ & $\begin{array}{l}\text { Chuang et al., } \\
2008\end{array}$ & $\begin{array}{l}\text { I-Hsin Biotechnology } \\
\text { Inc. }\end{array}$ \\
\hline \multirow{3}{*}{$\begin{array}{l}\text { Normal in } \\
\text { hybridization }\end{array}$} & $\begin{array}{l}P . \text { Brother Irene Irene 'Feng } \\
\text { Fong' (BII) }\end{array}$ & $2 n=4 x=76$ & Hsu et al., 2010 & Star Orchids \\
\hline & $\begin{array}{l}\text { P. Tai Lin Redangel 'V31' } \\
\text { (V31) }\end{array}$ & $2 n=4 x=76$ & Hsu et al., 2010 & Star Orchids \\
\hline & P. violacea & $2 n=2 x=38$ & Kao et al., 2001 & $\mathrm{NCYU}^{\mathrm{z}}$ \\
\hline
\end{tabular}

${ }^{z}$ NCYU: National Chiayi University. 


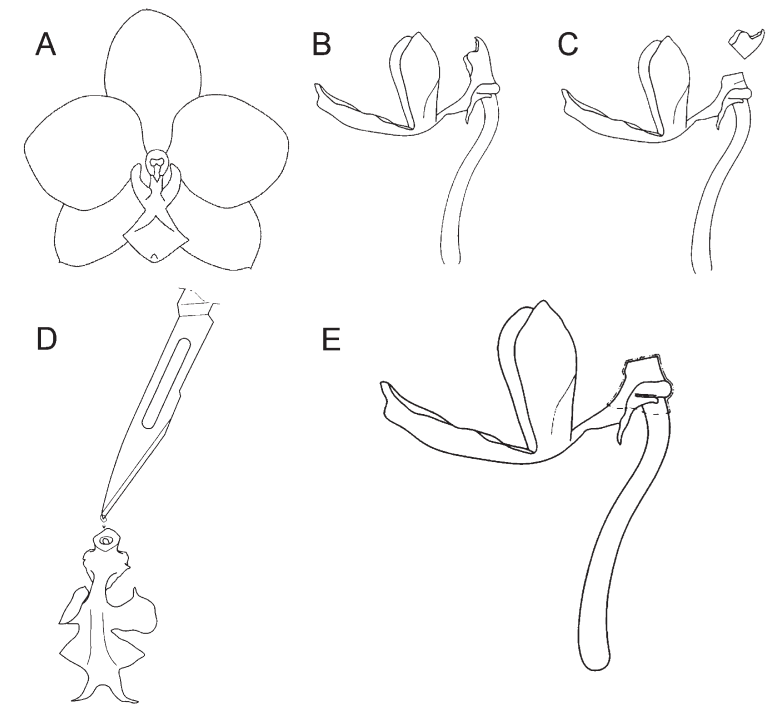

Fig. 1. Schematic illustration of the cut-column pollination method used in this study to overcome breeding barriers in Phalaenopsis Sunrise Goldmour 'KHM637', which had stigma closure problem after pollination. The sepals and petals of intact flower (A) of pistillate parent were removed from the base (B). The upper part of column was cut off, with the stigma cavity intact (C). Pollinia of pollen parent were then placed onto stigma cavity of pistillate parent (D). The stigma cavity was subsequently sealed with paraffin film (E). biotic seed germinating abilities according to the method recommended by Lin et al. (2008). Four to nine crossings were evaluated in each of crossing combinations.

\section{RESULTS}

\section{Crossing behaviors in self-pollination}

In the self-crossings, the three normal cultivars, Phalaenopsis Brother Irene Irene 'Feng Fong' (BII), $P$. Sogo Yukidian 'V3' (V3), and $P$. Tai Lin Red Angel 'V31' (V31), all showed $100 \%$ of stigma cavity closure at three days after pollination (DAP), $100 \%$ of in vivo pollen tube elongation at $7 \mathrm{DAP}$, and $100 \%$ capsule set at $60 \mathrm{DAP}$, and finally produced over 900 offsprings (Table 2). However, the stigma cavity closure and pollen tube elongation did not occur, and none of offspring had been produced in the self-crossings of $P$. Sunrise Goldmour 'KHM637' (SG) with difficulties in hybridization (Table 2).

\section{Crossing behaviors in reciprocal pollination}

To further elucidate breeding barriers, the cultivar with difficulties in hybridization (SG) was reciprocallycrossed with each of the three normal cultivars (BII, V3 and V31). Both phenomena of stigma cavity closure and in vivo pollen tube elongation did not occur when SG was used as the pistillate parent (Table 3). When BII, V3 and V31 were used as pistillate parents, the phenom-

Table 2. Occurrence of stigma cavity closure, pollen tube elongation, capsule set, and fertility in self-crossings ${ }^{z}$ of three normal Phalaenopsis cultivars and the cultivar of $P$. Sunrise Goldmour 'KHM637' with breeding barriers

\begin{tabular}{|c|c|c|c|c|c|}
\hline $\begin{array}{l}\text { Cultivar } \\
\text { name }^{y}\end{array}$ & $\begin{array}{l}\text { Stigma cavity } \\
\text { closure (\%) } \\
\text { (3 DAP) }\end{array}$ & $\begin{array}{l}\text { In vivo pollen tube } \\
\text { elongation }(\%) \\
\text { (7 DAP) }\end{array}$ & $\begin{array}{c}\text { Capsule set } \\
(\%) \\
(60 \mathrm{DAP})\end{array}$ & $\begin{array}{l}\text { Fertile } \\
\text { capsule } \\
(\%)\end{array}$ & $\begin{array}{c}\text { No. of } \\
\text { offsprings }\end{array}$ \\
\hline SG & $0 \mathrm{~b}^{\mathrm{x}}$ & $0 \mathrm{~b}$ & $0 \mathrm{~b}$ & $0 \mathrm{~b}$ & 0 \\
\hline BII & $100 \mathrm{a}$ & $100 \mathrm{a}$ & $100 \mathrm{a}$ & $100 \mathrm{a}$ & $>900$ \\
\hline V3 & $100 \mathrm{a}$ & $100 \mathrm{a}$ & $100 \mathrm{a}$ & $100 \mathrm{a}$ & $>900$ \\
\hline V31 & $100 \mathrm{a}$ & $100 \mathrm{a}$ & $100 \mathrm{a}$ & $100 \mathrm{a}$ & $>900$ \\
\hline
\end{tabular}

${ }^{z}$ Two separate experiments were conducted to investigate pollen tube development and fertility. Nine flowers were examined in each self-crossing.

${ }^{y}$ Abbreviations of the cultivar name as shown in Table 1. DAP, days after pollination.

${ }^{x}$ Mean separation within columns by LSD at $5 \%$ level.

Table 3. Occurrence of stigma cavity closure, pollen tube elongation, capsule set, and fertility in reciprocal-crossed combinations $^{z}$ of three normal Phalaenopsis cultivars and the cultivar of $P$. Sunrise Goldmour 'KHM637' with breeding barriers

\begin{tabular}{|c|c|c|c|c|c|}
\hline $\begin{array}{l}\text { Combination }{ }^{y} \\
\left(\text { 우 } \times \delta^{\lambda}\right)\end{array}$ & $\begin{array}{l}\text { Stigma cavity } \\
\text { closure (\%) } \\
\text { (3 DAP) }\end{array}$ & $\begin{array}{c}\text { In vivo pollen tube } \\
\text { elongation (\%) } \\
(7 \mathrm{DAP})\end{array}$ & $\begin{array}{c}\text { Capsule set } \\
(\%) \\
(60 \mathrm{DAP})\end{array}$ & $\begin{array}{l}\text { Fertile } \\
\text { capsule } \\
(\%)\end{array}$ & $\begin{array}{c}\text { No. of } \\
\text { offsprings }\end{array}$ \\
\hline $\mathrm{SG} \times \mathrm{BII}$ & $0 \mathrm{~b}^{\mathrm{x}}$ & $0 \mathrm{a}$ & 0 & 0 & 0 \\
\hline $\mathrm{SG} \times \mathrm{V} 3$ & $0 \mathrm{~b}$ & $0 \mathrm{a}$ & 0 & 0 & 0 \\
\hline $\mathrm{SG} \times \mathrm{V} 31$ & $0 \mathrm{~b}$ & $0 \mathrm{a}$ & 0 & 0 & 0 \\
\hline $\mathrm{BII} \times \mathrm{SG}$ & $77.8 \mathrm{a}$ & $11.1 \mathrm{a}$ & 0 & 0 & 0 \\
\hline $\mathrm{V} 3 \times \mathrm{SG}$ & $77.8 \mathrm{a}$ & $0 \mathrm{a}$ & 0 & 0 & 0 \\
\hline V $31 \times S G$ & $88.9 \mathrm{a}$ & $11.1 \mathrm{a}$ & 0 & 0 & 0 \\
\hline
\end{tabular}

${ }^{z}$ Two separate experiments were conducted to investigate pollen tube development and fertility. Nine flowers were examined in each reciprocal-crossing.

${ }^{y}$ Abbreviations of the cultivar name as shown in Table 1. DAP, days after pollination.

${ }^{x}$ Mean separation within columns by LSD at $5 \%$ level. 
ena of stigma cavity closure were observed at 3 DAP and reached $77.8 \%, 77.8 \%$ and $88.9 \%$, respectively, and in vivo pollen tube elongation were partially observed at 7 DAP and reached $11.1 \%, 0 \%$ and $11.1 \%$, respectively (Table 3). No offspring was obtained when using SG as either pollen or pistillate parent (Table 3).

\section{Efficacy of cut-column pollination method}

To explore performance of cut-column pollination method, the cultivar of SG with difficulty in hybridization was used as the pistillate parent, after the removal of the upper part of column but with the stigma cavity intact, and then pollinated with pollinia of three cultivars, BII, V3 and V31, and one species, $P$. violacea, respectively. The results showed that capsule sets collected at 60 DAP reached $22.2 \%, 77.8 \%, 100.0 \%$ and $75.0 \%$, for these four combinations used pollinia of BII, V3, V31 and P. violacea, respectively (Table 4). Capsule sets were achieved by cut-column pollination method in these four combinations (Fig. 2A, left). In contrast, the flower of SG without conducting procedures of cut-column pollination method wilted after pollination (Fig. 2A, right). Both the capsule fertility and offspring production were then examined using aseptic seed germination when mature capsule (Fig. 2B) was successfully obtained. The results showed that $55.6 \%-77.8 \%$ of fertile capsule formations were achieved except the combination of using pollinia from BII, and offsprings were successfully obtained from other three of these four combinations (Table 4). Some of these hybrid seedlings have been cultivated into healthy flowering plants (Fig. 2) for further selection and breeding.

Table 4. Effects of cut-column pollination method on capsule set, fertility, and offspring production in Phalaenopsis Sunrise Goldmour 'KHM637', the cultivar with stigma closure problem controlled by pistillate parent itself, used as the pistillate parent

\begin{tabular}{|c|c|c|c|c|}
\hline 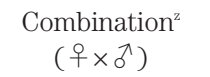 & $\begin{array}{c}\text { No. of } \\
\text { crossing }\end{array}$ & $\begin{array}{l}\text { Capsule set \% } \\
\qquad(60 \text { DAP })\end{array}$ & $\begin{array}{c}\text { Fertile capsule } \\
\text { (\%) }\end{array}$ & $\begin{array}{c}\text { No. of } \\
\text { offsprings }\end{array}$ \\
\hline $\mathrm{SG} \times \mathrm{BII}$ & 9 & $22.2 c^{y}$ & $0 \mathrm{~b}$ & 0 \\
\hline $\mathrm{SG} \times \mathrm{V} 3$ & 9 & $77.8 \mathrm{~b}$ & $77.8 \mathrm{a}$ & 83 \\
\hline $\mathrm{SG} \times \mathrm{V} 31$ & 9 & $100.0 \mathrm{a}$ & $55.6 \mathrm{a}$ & 45 \\
\hline $\mathrm{SG} \times P$. violacea & 4 & $75.0 \mathrm{~b}$ & $75.0 \mathrm{a}$ & 149 \\
\hline
\end{tabular}

${ }^{z}$ Abbreviations of the cultivar name as shown in Table 1. DAP, days after pollination.

${ }^{y}$ Mean separation within columns by LSD at 5\% level.
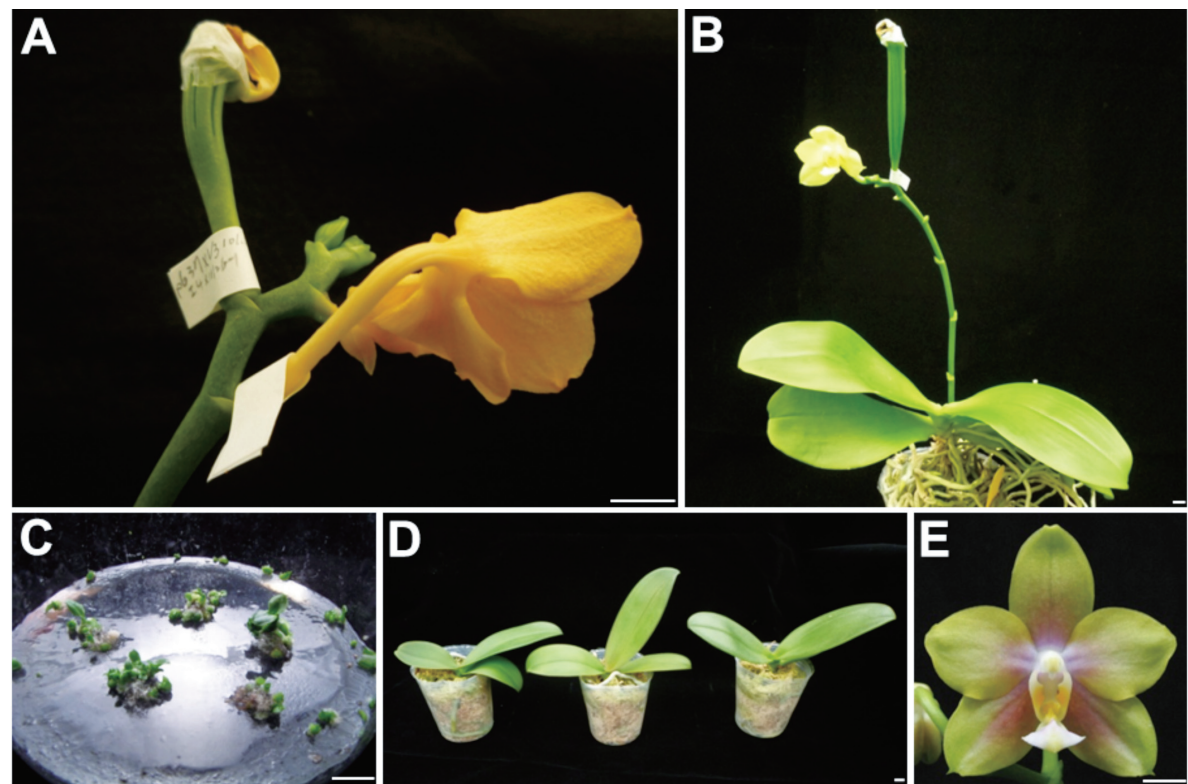

Fig. 2. The performance of using cut-column pollination method to overcome breeding barriers in Phalaenopsis Sunrise Goldmour 'KHM637', which had stigma closure problem after pollination. The capsule was set following cut-column pollination method (A, left). The flower wilted at 16 days after pollination without cut-column (A, right). Mature capsule was successfully obtained (B). Seeds germinated under aseptic culture (C). The potted hybrid seedlings were obtained (D). The flower of a hybrid derived from crossing the cutcolumn, pistillate parent $P$. Sunrise Goldmour 'KHM637' with the pollen parent $P$. violacea (E). Scale bars, $1 \mathrm{~cm}$. 


\section{DISCUSSION}

Breeding barriers in producing hybrids by intergeneric, inter- and intraspecific hybridization in Phalaenopsis have been observed. However, the causes and mechanisms of such breeding barriers have not been thoroughly studied. Approaches to elucidate the basis of reproductive barriers between specific crossing combinations in Phalaenopsis have been conducted by our research team (Chuang et al., 2008; Chuang et al., 2013; Hsu et al., 2010). Six cultivars which are known to be difficult in hybridization, including Doritaenopsis Ever Spring Prince '\#1' (ESP), D. Queen Beer 'KHM 159' (QB), D. Taida Salu 'KHM 101' (TS), P. Brother Girl 'B' (BG), $P$. Taipei Gold 'STM' (TG), and $P$. Sunrise Goldamour 'KHM637' (SG), and three cultivars with normal behaviors in crossing, including $P$. Brother Irene Irene 'Feng Fong' (BII), $P$. Sogo Yukidian 'V3' (V3), and $P$. Tai Lin Red Angel 'V31' (V31), were investigated for the mechanisms underlying the crossing barriers.

The chromosome numbers analyzed by root tip squash showed that the five of selected cultivars with difficulties in hybridization are triploids with $2 \mathrm{n}=3 \mathrm{x}=57$ chromosomes, while SG and the other three normal cultivars are tetraploids with $2 \mathrm{n}=4 \mathrm{x}=76$ chromosomes (Chuang et al., 2008; Hsu et al., 2010). These results suggested that the triploidy of these five selected cultivars might have contributed to their crossing difficulties.

The crossing results showed that the closure of stigma cavities occurred in TS and BG, while such stigma closure was never observed when ESP or QB was used as the pollen parent in crosses (Hsu et al., 2010). Neither closure of the stigma cavities nor elongation of pollen tubes occurred when TG or SG was self-crossed, or was used as the pistillate parent during intraspecfic crossing (Chuang et al., 2008). These results suggested that crossing difficulties in those selected cultivars might be caused by odd chromosome sets and some other factors of pollen or pistillate parents.

\section{Stigma closure problem of $\boldsymbol{P}$. Sunrise Goldmour 'KHM637' not limited to specific crossing combina- tions}

$P$. Sunrise Goldmour 'KHM637' (SG) is known to have stigma closure problem after pollination and be difficult in hybridization (Chuang et al., 2008). After pollination a series of physiological and morphological changes, such as pollen tube growth and fertilization to the seed set may develop. Usually the stigma cavity of Phalaenopsis flower would close 48 hours after pollination (Goh et al., 1982; O'Neill et al., 1993; Zhang and O'Neill, 1993). Use of fluorescence to monitor pollen tube behavior in the style and ovary provided a rapid and correct interpretation in studying self- and cross-incompatibility. Therefore, the phenomena of stigma cavity closure and pollen tube behavior in the column could be easily observed for evaluating the pollination process of each crossing combination.

In the self-crossings, as expected the three normal cultivars, BII, V3 and V31, all showed stigma cavity closure and pollen tube elongation, and finally produced offsprings (Table 2). However, the stigma cavity closure and pollen tube elongation did not occur, and none of offspring had been produced in the self-crossings of SG (Table 2).

To further elucidate breeding barriers, SG was reciprocally-crossed with each of the three normal cultivars (BII, V3 and V31). Both phenomena of stigma cavity closure and in vivo pollen tube elongation did not occur when SG was used as the pistillate parent (Table 3). The failure to produce any offspring in self- and reciprocal crossings of SG might be caused by some uncertain maternal parent factors in itself and not limited to specific crossing combinations, since stigma cavity closure and pollen tube elongation did not occur when it was used as a pistillate parent, no matter what pollen parents used (Tables 2 and 3; Fig. 2A, right).

\section{Stigma closure problem not the only reason accountable for failure to produce offspring in crossing of $P$. Sunrise Goldmour 'KHM637'}

Several methods including the stigma cavity sealing with paraffin film, applying different quantity of pollinia, and auxins treatments have been conducted by us to attempt to overcome breeding barriers in $P$. Sunrise Goldmour 'KHM637' (SG) and P. Taipei Gold 'STM' (TG) (Chuang et al., 2008). However, in vivo pollen tube elongation did not occur by sealing stigma cavity with paraffin film when SG or TG was self-crossed, or was used as the pistillate parent and pollinated with pollonia of V3 (Chuang et al., 2008). Obviously the effect of stigma closure problem after pollination could not be corrected simply by sealing.

The postpollination development in orchid flowers is precisely and completely triggered by pollination. This postpollination developmental syndrome includes the induction and coordination of ovary and ovule development in preparation for fertilization. The development of the ovary as well as other aspects of the postpollination syndrome has an absolute requirement for the participatory action of auxin (Zhang and O'Neill, 1993). It has long been proposed that the causative agent in the postpollination response is auxin deposited on the stigma with the pollinia (Burg and Dijkman, 1967). Indeed, there are a number of reports indicated that auxin is a natural component of orchid pollen (Arditti, 1979; Stead, 1992).

In light of this association between auxin and postpollination response in orchids, the authors have also examined the effects of quantity of pollinia and auxin on the stigma cavity closure and in vivo pollen tube elongation in crossing combinations of using $\mathrm{SG}$ or $\mathrm{TG}$ as the pistillate parent and V3 as the pollen parent (Chuang et al., 2008). However, both phenomena of stigma cavity closure and in vivo pollen tube elongation did not occur even when four pollinia were used in each pollination. The authors found that exogenous application of $2.9 \mathrm{mM}$ indole-3-acetic acid (IAA) or naphthalene acetic acid (NAA) to the stigmatic surface of SG and TG results in occurrence of stigma cavity closure, however, not in in 
vivo pollen tube elongation, capsule set, and offspring production. These results indicated that stigma closure problem might not be the only reason accountable for failure to produce offspring in crossing of $P$. Sunrise Goldmour 'KHM637'.

\section{Applicability of the cut-column pollination method less limited to pollen parents}

Sexual barriers preventing intra- or interspecific hybridization have been distinguished into pre- and post-fertilization barriers. The nature of the barrier determines the method to be used to overcome the specific barrier. A range of techniques such as pollen heating, electrical stimulation, chemical treatment, bud pollination, mentor pollination, style grafting, cut-style and placental pollination have been developed to overcome pre-fertilization barriers for diverse crops (Janson, 1993; Janson et al., 1993; Magdalita et al., 1998; Ronald and Ascher, 1975; Shen and Liao, 1976; Van Tuyl et al., 1988; Van Tuyl et al., 1991; Vervaeke et al., 2004; Visser, 1983).

The authors have developed a technique for overcoming breeding barriers in Phalaenopsis and named the technique as "cut-column pollination method" (Chuang et al., 2013), since the technique was modified from the cut-style pollination using in lily (Janson et al., 1993; Van Tuyl et al., 1991) and a distinguishing feature of the Orchidaceae is the gynostemium or column, which is the fusion of the style, stigma, and stamens.

The authors have also demonstrated that this cutcolumn pollination method proved to overcome breeding barriers in $P$. Taipei Gold 'STM' (TG), known to have stigma closure problem after pollination and be difficult in hybridization (Chuang et al., 2013). P. Sunrise Goldmour 'KHM637' (SG) has shown similar hybridization behavior to TG (Chuang et al., 2008). In this study, the authors aimed to examine the efficacy of cut-column pollination method for overcoming the breeding barriers of SG, and to explore the applicable extensibility of the given method.

The cultivar of SG, used as the pistillate parent, was treated with cut-column pollination method and then pollinated with pollinia of three cultivars, BII, V3 and V31, and one species, $P$. violacea, respectively. The results showed that capsule sets were all achieved by cut-column pollination method in these four combinations, and both the capsule fertility and offspring production were mostly obtained except the combination of using pollinia from BII (Table 4). The similar situation was also found in combinations which cultivar of TG, used as the pistillate parent, was treated with cut-column pollination method and then pollinated with pollinia of three cultivars, BII, V3 and V31, and two species, $P$. violacea and P. fasciata, respectively (Chuang et al., 2013). These results suggested that the failure to produce any offspring in combination of SG and BII, and of TG and BII might be caused by similar uncertain interaction between partners of each combination.

In a comparison of the cut-style technique using in lily (Janson et al., 1993; Van Tuyl et al., 1991), it was shown that some pre-fertilization barriers in Phalaenopsis could be circumvented by using the cutcolumn pollination method. If the sterility was caused due to existence of pre-fertilization barriers in upper part of column, fertility might be restored by the cut-column pollination method. In this way pollinia bypassed column barriers which could inhibit pollen tube growth, without incidence of stigma cavity closure.

In conclusion, the cut-column pollination method might be applicable to other Phalaenopsis cultivars with similar crossing behaviors of $P$. Sunrise Goldmour 'KHM637' and $P$. Taipei Gold 'STM' for overcoming the crossing barriers, and the applicability of the given method tends to be less limited to pollen parents without breeding barriers.

\section{REFERENCES}

Ardltti, J. 1979 Aspects of the physiology of orchids. Adv. Bot. Res. 7: 421-655

Burg, S. P. and M. J. Dijkman 1967 Ethylene and auxin participation in pollen induced fading of Vanda orchid blossoms. Plant Physiol. 42: 1648-1650

Christenson, E. A. 2001 Phalaenopsis: A monograph. International Phalaenopsis Alliance, Timber Press, Inc. U.S.A.

Chuang, H. T., K. L. Huang, and S. T. Hsu. 2013 Using cut-column pollination method to overcome breeding barriers in Phalaenopsis Taipei Gold 'STM'. J. Taiwan Soc. Hort. Sci. 59: $103-111$

Chuang, H. T., S. T. Hsu, and T. M. Shen. 2008 Breeding barriers in yellow Phalaenopsis orchids. J. Taiwan Soc. Hort. Sci. 54: $59-66$

Customs Administration. 2012 Trade statistics. Trade statistics search system. <http://www.customs.gov.tw/StatisticWeb/News. aspx>

Goh, C. J., M. S. Strauss and J. Arditti 1982 Flower induction and physiology in orchids, p. 213-241. In: J. Arditti (ed.). Orchid Biology: Reviews and Perspectives, II. Cornell Univ. Press, Ithaca, N.Y. U.S.A.

Hsu, S. T., H. T. Chuang, and T. M. Shen 2010 Breeding barriers in red Phalaenopsis orchids. Acta Hort. 878: 145-152

Janson, J. 1993 Placental pollination in Lilium longiflorum Thunb. Plant Sci. 90: 105-115

Janson, J., M. C. Reinders, J. M. Van Tuyl and C. J. Keijzer 1993 Pollen tube growth in Lilium longiflorum following different pollination techniques and flower manipulations. Acta Botanica Neerlandica 42: 461-472

Kao, Y. Y., S. B. Chang, T. Y. Lin, C. H. Hsieh, Y. H. Chen, W. H. Chen, and C.C. Chen. 2001 Differential accumulation of heterochromatin as a cause for karyotype variation in Phalaenopsis orchids. Ann. Bot. 87: 387-395

Kho, Y. O. and J. Baër. 1968 Observing pollen tubes by means of fluorescence. Euphytica 17: 298-302

Lin, H. J., H. T. Chuang, S. T. Hsu and T. M. Shen 2008 Effects of developmental temperature and capsule harvest time on the aseptic seed germination in Phalaenopsis aphrodite subsp. formosana. Plant Nursery 10: 59-71

Magdalita, P. M., R. A. Drew, I. D. Godwin and S. W. Adkins 1998 An efficient interspecific hybridization protocol for Carica papaya L. $\times$ C. cauliflora Jacq. Aust. J. Exp. Agric. 38: 523-530

O' Neill, S. D., J. A. Nadeau, X. S. Zhang, A. Q. Bui and A. H. Halevy 1993 Interorgan regulation of ethylene biosynthetic genes by pollination. Plant Cell 5: 419-432

Ronald, W. G. and P. D. Ascher 1975 Effects of high temperature treatments on seed yield and self incompatibility in Chrysanthemum. Euphytica 24: 317-322

Royal Horticultural Society. 2013 Plant registration. <http://www. 
rhs.org.uk/Plants/Plant-science/Plant-registration/Orchids>

Shen, T. F. and C. I. Liao 1976 Factors affecting the degree of selfincompatibility and the breaking of self-incompatibility in Yehsen cabbage. Sci. Dev. 4: 2298-2305

Stead, A. D. 1992 Pollination-induced flower senescence: A review. Plant Growth Regul. 11: 13-20

Van Tuyl, J. M., M. P. Van Diën, M. G. M. Van Creij, T. C. M. Van Kleinwee, J. Franken and R. J. Bino 1991 Application of in vitro pollination, ovary culture, ovule culture and embryo rescue for overcoming incongruity barriers in interspecific Lilium crosses. Plant Science 74: 115-126

Van Tuyl, J. M., T. P. Straathof, R. J. Bino and A. A. M. Kwakkenbos
1988 Effect of three pollination methods on embryo development and seed set in intra- and interspecific crosses between seven Lilium species. Sex Plant Reprod. 1: 119-123

Vervaeke, I., R. Delen, J. Wouters, R. Deroose and M. P. de Proft 2004 Semi in vivo pollen tube growth of Aechmea fasciata. Plant Cell, Tissue Organ Cult. 76: 67-73

Visser, T. 1983 The role of pioneer pollen in compatible and incompatible pollinations of apple and pear. Acta Hortic. 139: 51-57

Zhang, X. S. and S. D. O'Neill 1993 Ovary and gametophyte development are coordinately regulated by auxin and ethylene following pollination. Plant Cell 5: 403-418 